\title{
PENINGKATAN KEMAMPUAN MENULIS TEKS BERITA MENGGUNAKAN MODEL SNOWBALL THROWING PADA SISWA KELAS VIII-B SMP SWASTA IMELDA MEDAN TAHUN PELAJARAN 2018/2019
}

\author{
Valentina Febriyanti ${ }^{1}$, Panigoran Siburian ${ }^{2}$ \\ Universitas Prima Indonesia ${ }^{1}$, Universitas Prima Indonesia ${ }^{2}$ \\ Pos-el: valentina.sibarani16@gmail.com ${ }^{1}$, panigoransiburian@gmail.com²
}

\begin{abstract}
ABSTRAK
Penelitian ini bertujuan untuk mengetahui peningkatan hasil pembelajaran kemampuan menulis teks berita menggunakan model pembelajaran Snowball Throwing pada siswa kelas VIII-B SMP Swasta Imelda Medan Tahun Pelajaran 2018/2019. Model Snowball Throwing pengembangan dari model pembelajaran diskusi dan merupakan bagian dari model pembelajaran kooperatif. Dalam konteks pembelajaaran Snowball Throwing diterapkan dengan melempar segumpalan kertas untuk menunjuk siswa yang diharuskan menjawab soal dari guru. Alasan yang mendasari dilakukannya penelitian ini yaitu kurangnya sarana dan prasarana mengakibatkan kemampuan menulis teks berita menjadi relatif rendah. Jenis penelitian yang digunakan dalam penelitian adalah penelitian deskriptif kualitatif. Subjek penelitian ini guru Bahasa Indonesia dan siswa kelas VIII-B SMP Swasta Imelda Medan. Hasil yang ditemukan adalah adanya peningkatan hasil pembelajaran kemampuan menulis teks berita menggunakan model pembelajaran Snowball Throwing setelah melalui dua siklus dengan rincian peningkatan dari $59 \%$ yang tuntas menjadi $82 \%$.
\end{abstract}

Kata Kunci: Menulis Berita, Snowball Throwing.

\section{ABSTRACT}

This study aims to determine the increase in learning outcomes of the ability to write news text by using the snowball throwing learning model in class VIII-B SMP Swasta Imelda Medan Tahun Pelajaran 2018/2019. The snowball throwing model develops from a discussion learning model and is part of the cooperative learning model. In the context of snowball throwing learning is applied by throwing a piece of paper to designate students who are required to answer questions from the teacher. The reason underlying this research is the lack of facilities and infrastructure resulting in the ability to write news texts to be relatively low. The type of research used in the research is qualitative descriptive research. The subject of this research is Indonesian language teachers and class students VIII-B SMP Swasta Imelda Medan. The results found were and increase in the learning outcomes of the ability to write news text using the snowball throwing learning model after going through two cycles with details of an increase of $59 \%$ which finished to $82 \%$.

Keywords: Write News, Snowball Throwing.

\section{PENDAHULUAN}

Menulis merupakan suatu keterampilan yang menuangkan gambaran lambang-lambang yang digunakan untuk berkomunikasi secara tidak langung Keterampilan menulis merupakan salah satu aspek berbahasa yang sangat penting. Dikatakan demikian karena menulis membutuhkan proses berpikir yang baik dalam 
menuangkan ide/gagasan. Selain itu, kegiatan menulis dapat mengekspresikan suatu pencapaian ide, pikiran, perasaan dan kondisi seseorang kepada orang lain menggunakan bahasa tulisan sehingga dapat dipahami oleh pembaca.

Dalman (2014: 3), mengatakan bahwa menulis merupakan suatu kegiatan komunikasi berupa penyampaian pesan secara tertulis kepada pihak lain dengan menggunakan bahasa tulis sebagai alat atau medianya. Menulis merupakan sebuah proses kreatif menuangkan gagasan dalam bentuk bahasa tulis dalam tujuannya misalnya memberitahu, meyakinkan atau menghibur. Hasil dari proses ini disebut dengan istilah karangan atau tulisan.

Dengan demikian, keterampilan menulis merupakan salah satu cara seseorang untuk mengembangkan kemampuan yang dimilikinya untuk dapat melakukan suatu proses kegiatan menulis untuk mengungkapkan suatu ide/gagasan, perasaan, pendapat, dan situasi seseorang serta mengekspresikan perasaan dengan menggunakan bahasa tulisan. Menulis dapat diartikan sebagai suatu alat untuk menyampaikan informasi melalui ide/gagasan yang disusun sesuai dengan kebutuhankebutuhan pembaca sekaligus menjadi sumber utama terciptanya kreativitas seseorang.

Assegaff (Barus 1983: 23-24), diharapkan bisa memberikan pengertian dan pemahaman yang lebih luas lagi kepada kita mengenai berita. Spencer (Barus 1983: 23-24) misalnya, dalam News Writing menyatakan, berita adalah suatu kenyataan atau ide yang benar yang dapat menarik perhatian sebagian besar pembaca.

Sesuai dengan kompetensi dasar 4.2 dalam silabus Bahasa Indonesia kelas VIII, peserta didik diharapkan mampu mengungkapkan ide-idenya dalam bentuk tulisan. Menulis teks berita sangat penting karena menulis teks berita itu memerlukan kreativitas berpikir.
Namun kenyataannya berbeda dengan yang ada di sekolah SMP Swasta Imelda Medan bahwa kemampuan menulis peserta didik masih rendah, kurangnya minat belajar siswa, sulit menuangkan ide, kurangnya penggunaan kosakata, kurangnya percaya diri, keaktifan siswa dalam belajar masih rendah, kurangnya motivasi, hasil belajar menulis teks berita masih relatif rendah dan model pembelajaran yang kurang tepat dengan materi pembelajaran.

Dalam penelitian ini guru menggunakan model Snowball Throwing dalam pembelajaran Bahasa Indonesia dalam pembelajaran menulis teks berita. Model ini menuntut keterlibatan penuh seorang pembelajaran untuk memperoleh berbagai informasi dan pengalaman dalam belajar tersebut.

Penelitian selanjutnya, Eli (2010) dalam jurnal yang berjudul "Peningkatan Keterampilan Menulis Teks Berita dengan Pendekatan Komunikatif melalui Model Pembelajaran Snowball Throwing siswa kelas VIII-A SMP Negeri 4 Juwana", menyatakan bahwa keterampilan menulis teks berita dan variabel pendekatan komunikatif melalui model pembelajaran snowball throwing. Pengumpulan data pada siklus I dan siklus II menggunakan teknik tes dan nontes dengan penerapan teknik pembelajaran. Tes yang digunakan adalah tes untuk kerja berupa penugasan menulis poster, sedangkan teknik nontes yang digunakan berupa observasi, catatan harian siswa, catatan hari guru, wawancara, dan dokumentasi foto. Penelitian ini menggunakan analisis data kuantitatif dan kualitatif. Teknik kuantitatif digunakan untuk menganalisis dan membandingkan hasil tes siklus I dan siklus II. Sementara teknik kualitatif digunakan untuk menganalisis dan membandingkan hasil nontes siklus I dan siklus II. Penggunaan pendekatan komunikatif melalui model pembelajaran snowball throwing pada pembelajaran terbukti dapat meningkatkan siswa 
dalam menulis teks berita. Peningkatan ini dapat diketahui dari hasil tes yang dilakukan pada siswa kelas VIII-A SMP Negeri 4 Juwana, Pati yang meliputi tes prasiklus, siklus I dan siklus II. Pada prasiklus diperoleh nilai rata-rata kelas sebesar

60,12. Pada siklus I diperoleh nilai rata-rata kelas sebesar 68,21. Terjadi peningkatan hasil keterampilan menulis teks berita sebesar 8,09 atau 13,46\%. Pada siklus II diperoleh nilai rata-rata kelas sebesar 79,32. Jadi peningkatan keterampilan menulis teks berita dari prasiklus ke siklus II adalah 19,20 atau $31,94 \%$ dan dari siklus I sampai siklus II adalah 19,20 atau 11,11 atau $11,29 \%$.

\section{METODE PENELITIAN}

Penelitian ini dilaksanakan di SMP Swasta Imelda Medan di kelas VIII-B tepatnya pada semester genap Tahun Pelajaran 2018/2019. Subjek penelitian ini adalah siswa kelas VIII-B SMP Swasta Imelda Medan. Adapun model PTK yang dimaksud adalah model yang dikemukakan Kemmish dan Mc Taggart. Desain model PTK tersebut adalah sebagai berikut:

Jenis data yang digunakan dalam PTK berupa data kualitatif. Dalam penelitian kualitatif, penulis menggunakan teknik cuplikan purposive sampling (sampel bertujuan), karena di dalam teknik ini peneliti memilih informan yang dianggap mengetahui permasalahan dan dapat dipercaya untuk menjadi sumber data yang memiliki kebenaran dan pengetahuan yang mendalam. Data kualitatif berupa hasil observasi guru (wawancara) dan keaktifan siswa. Sumber data adalah siswa, guru dan dukomen. Teknik pengumpulan data teknik tes dalam bentuk uraian, observasi dan dokumentasi.

Penelitian ini dilaksanakan dalam dua siklus. Setiap siklus terdari empat pertemuan dimulai dari 15 April sampai
24 April 2019. Terdapat empat komponen pokok dari PTK yaitu perencanaan, pelaksanaan, observasi dan refleksi. Adapun prosedur penelitiannya sebagai berikut.

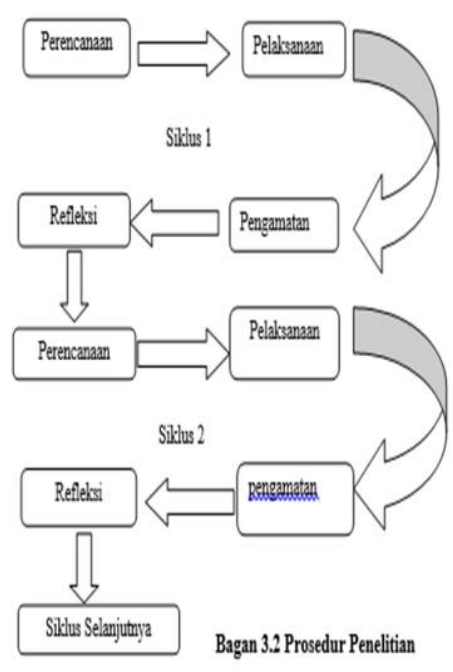

Untuk mengetahui keefektifan suatu model atau metode harus menggunakan teknik analisis data. Pada PTK digunakan analisis data kualitatif. Untuk menghitung tingkat ketuntasan belajar adalah:

$p$

$=\frac{\sum \text { siswa yang tuntas belajar }}{\sum \text { siswa }} \times 100 \%$

$\mathrm{p}=$ persentase siswa yang lulus KKM

Rumus untuk menentukan kriteria ketuntasan ketuntasan klasikal

k.k.k $=\frac{\text { Jumlah siswa yang tuntas }}{\text { Jumlah keseluruhan siswa }} \times 100 \%$

Rumus mencari persentasi peningkatan antar siklus

Persentasi $(\%)=$ KKK Siklus II - KKK siklus I

\section{HASIL DAN PEMBAHASAN Hasil Penelitian}

Hasil penelitian yang dilakukan pada prasiklus, siklus I, dan siklus II di kelas VIII-B SMP Swasta Imelda Medan menunjukkan adanya peningkatan kemampuan menulis teks berita siswa, keaktifan siswa dan observasi guru pada pokok pembelajaran menulis teks berita 
dengan menggunakan model pembelajaran Snowball Throwing. Berdasarkan hasil penelitian yang diperoleh peneliti, tes kemampuan menulis teks berita siswa mengalami peningkatan dari prasiklus, siklus I dan siklus II. Peningkatan tes kemampuan menulis teks berita siswa dapat dilihat dari tabel berikut.

Tabel 1. Rekapitulasi Peningkatan Hasil Nilai Tes Kemampuan Teks Berita Pada Siswa di kelas

\section{VIII-B Pada Prasiklus, Siklus I dan Siklus II $^{\mathrm{a}}$}

\begin{tabular}{|c|c|c|c|c|c|}
\hline $\begin{array}{c}\text { Rentang } \\
\text { Nilai }^{\mathbf{b}}\end{array}$ & $\begin{array}{l}\text { Prasik } \\
\text { lus }^{c}\end{array}$ & $\begin{array}{c}\text { Sikl } \\
\text { us } \\
\text { I }^{\mathbf{d}}\end{array}$ & $\begin{array}{c}\text { Sikl } \\
\text { us } \\
\text { II }^{\mathrm{e}} \\
\end{array}$ & $\begin{array}{c}\text { Peningk } \\
\operatorname{atan}^{\mathrm{f}}\end{array}$ & $\begin{array}{c}\text { Keteran } \\
\text { gan }^{\mathrm{g}}\end{array}$ \\
\hline 93-100 & - & - & - & - & $\begin{array}{c}\text { Mening } \\
\text { kat }\end{array}$ \\
\hline $84-92$ & - & 4 & 11 & 4 & $\begin{array}{c}\text { Mening } \\
\text { kat }\end{array}$ \\
\hline $75-83$ & 3 & 16 & 17 & 3 & $\begin{array}{c}\text { Mening } \\
\text { kat }\end{array}$ \\
\hline$\leq 75$ & 31 & 14 & 6 & - & - \\
\hline Jumlah & 34 & 34 & 34 & - & - \\
\hline $\begin{array}{l}\text { Nilai } \\
\text { Tertinggi }\end{array}$ & 80 & 84 & 88 & 12 & $\begin{array}{c}\text { Mening } \\
\text { kat }\end{array}$ \\
\hline $\begin{array}{l}\text { Nilai } \\
\text { Terendah }\end{array}$ & 40 & 52 & 56 & - & - \\
\hline $\begin{array}{l}\text { Persentase } \\
\text { Ketuntasa } \\
\text { n Klasikal }\end{array}$ & $91 \%$ & $\begin{array}{l}59 \\
\%\end{array}$ & $\begin{array}{l}82 \\
\%\end{array}$ & - & - \\
\hline $\begin{array}{l}\text { Persentase } \\
\text { Yang } \\
\text { Tidak } \\
\text { Tuntas }\end{array}$ & $9 \%$ & $\begin{array}{l}41 \\
\%\end{array}$ & $\begin{array}{l}18 \\
\%\end{array}$ & - & - \\
\hline $\begin{array}{l}\text { Presentase } \\
\text { Ketuntasa } \\
\text { n Klasikal } \\
\text { non tes }\end{array}$ & - & $\begin{array}{l}41 \\
\%\end{array}$ & $\begin{array}{l}88 \\
\%\end{array}$ & - & - \\
\hline $\begin{array}{l}\text { Presentase } \\
\text { Ketidaktu } \\
\text { ntasan } \\
\text { Klasikal } \\
\text { non tes }\end{array}$ & - & $\begin{array}{l}59 \\
\%\end{array}$ & $\begin{array}{l}29 \\
\%\end{array}$ & - & - \\
\hline
\end{tabular}

\section{Pembahasan}

Pada proses pembelajaran dimulai dari prasiklus, siklus I dan siklus II yang telah dilaksanakan menggunakan model pembelajaran Snowball Throwing yang bertujuan untuk melakukan perbaikan dari kondisi awal siswa pada kegiatan pembelajaran prasiklus yaitu yang tuntas sesuai dengan KKM 9\% atau terdapat 3 siswa dan yang tidak tuntas 91\% terdapat 31 siswa. Kemudian pembelajaran siklus I agar dapat mencapai target kriteria ketuntasan minimal 75 dan ketuntasan klasikal siswa $75 \%$. Adapun hasilnya siswa yang lulus mendapatkan standar KKM 75 hanya 20 siswa $59 \%$ dan presentase ketuntasan klasikal nontes siklus I mencapai $41 \%$ atau hanya 14 siswa yang termasuk kategori "Baik". Sedangkan siswa yang belum lulus mendapatkan nilai $\leq 75$ ada 14 siswa $41 \%$ dan presentase ketidaktuntasan klasikal non tes siklus I mencapai 59\% atau terdapat 20 siswa yang termasuk kategori "Kurang". Pada proses siklus I indikator keberhasilan pada penilaian ketuntasan klasikal siswa baik dari tes maupun nontes belum sesuai atau melampaui $\geq$ $75 \%$ sehingga dapat disimpulkan belum tercapai.

Melihat dari siklus I tersebut perlu dilakukan perbaikan dari permasalahan yang ada sehingga peneliti mengidentifikasi dan merencanakan perbaikannya dengan melakukan tindakan proses pembelajaran di siklus II agar pembelajaran menulis teks berita siswa dapat meningkat sesuai nilai KKM pelajaran Bahasa Indonesia yaitu 75.

Proses pembelajaran siklus II pun masih menggunakan model pembelajaran Snowball Throwing. Adapun hasil yang mendapatkan nilai $\geq$ 75 mencapai 28 siswa (82\%) dan presentase ketuntasan klasikal nontes siklus II mencapai $88 \%$ atau terdapat 30 siswa yang termasuk kategori "Baik". Sedangkan siswa yang belum lulus mendapatkan nilai $\leq 75$ adalah 6 siswa (18\%) dan presentase ketuntasan klasikal nontes siklus II mencapai $12 \%$ atau hanya 4 siswa yang termasuk kategori "Kurang". Oleh karena itu, proses pembelajaran Bahasa Indonesia yang menerapkan model pembelajaran Snowball Throwing dapat meningkatkan kemampuan menulis teks berita siswa kelas VIII-B Swasta Imelda Medan. 
Tahap tindakan yang telah dilakukan dalam penelitian ini adalah peningkatan menulis teks berita menggunakan model Snowball Throwing. Pemilihan model tersebut merupakan upaya untuk mengatasi permasalahan yang dihadapi guru dalam rangka meningkatkan keterampilan siswa dalam menulis teks berita.

Model Snowball Throwing menjadikan siswa lebih aktif dan antusias saat proses pembelajaran berlangsung. Siswa dituntut untuk berkonsentrasi penuh saat menulis teks berita. Siswa lebih berperan aktif saat peneliti yang beraktivitas sebagai guru memberikan kesempatan kepada siswa untuk berimajinasi pada saat pembelajaran menulis teks berita dilakukan dengan menggunakan model Snowball Throwing untuk proses penggalian pemahaman siswa dari apa yang telah diamatinya.

Model pembelajaran ini lebih menekankan peran siswa dalam pembelajaran, peneliti hanya berperan sebagai fasilitator dalam pembelajaran seperti mengondisikan keadaan pembelajaran yang sedang berlangsung di kelas. Siswa hanya menentukan unsur-unsur berita, hingga hasil akhirnya mampu memahami isi teks berita dari kegiatan menulis siswa yang dapat dilihat hasilnya dari penilaian pengerjaan tes menulis berita siswa disetiap akhir siklus pembelajaran.

Pada proses pembelajaran di siklus II yang masih menerapkan model Snowball Throwing sudah mengalami peningkatan. Hal ini karena sudah banyak siswa yang mau mengikuti intruksi dari peneliti dalam proses pembelajaran menulis teks berita sehingga mendorong siswa untuk memiliki keinginan dalam menulis teks berita mereka sudah terbiasa dan sangat antusias untuk melakukan pembelajaran dengan model Snowball Throwing sebagai penggali pemahaman siswa dari hal-hal yang telah dipelajarinya selama proses pembelajaran berlangsung.

Pada proses pembelajaran berlangsung, pengajaran menggunakan model Snowball Throwing terbukti memiliki dampak terhadap peningkatan menulis teks berita dibandingkan dengan pengetahuan siswa itu sendiri dapat dilihat melalui tabel 4.9 tabel peningkatan hasil tes dan non tes dari prasiklus, siklus I dan siklus II.

\section{SIMPULAN}

Berdasarkan analisis hasil penelitian dan pembahasan pada bab sebelumnya, peneliti menyimpulkan bahwa menggunakan model Snowball Throwing pada pembelajaran Bahasa Indonesia dengan sub pokok menulis teks berita pada siswa kelas VIII-B SMP Swasta Imelda Medan dapat meningkatkan kemampuan menulis teks berita siswa, keaktifan siswa dan performansi guru. Hal ini terbukti dari hasil siswa dan penelitian guru setiap mengajar mengalami peningkatan setiap siklusnya.

\section{DAFTAR PUSTAKA}

Arikunto, Suharsimi, 2014. Prosedur Penelitian. Jakarta: Rineka Cipta.

Arikunto, Suharsimi, 2017. Penelitian Tindakan Kelas. Jakarta: Bumi Aksara

Barus, S. W. 2010. Jurnalistik: Petunjuk Teknik Menulis Berita. Jakarta: Erlangga

Dalman, 2014. Keterampilan Menulis. Rajawali Pres, Jakarta.

Shoinim, Aris, 2016. 68 Model Pembelajaran Inovatif dalam Kurikulum 2013. Yogyakarta: Ruzz Media.

Sugiyono, 2017. Metode Penelitian Kuantitatif Kualitatif dan $R \& D$. Bandung: Alfabeta. 